\title{
Effects of $\mathrm{Ba}^{2+}$ on Secretory $\mathrm{K}^{+}$Movement and Electrical Properties of the Early Distal Tubule of Triturus Kidney
}

\author{
Hisato SAKamoto* and Takeshi Hoshi \\ Department of Physiology, Faculty of Medicine, \\ University of Tokyo, Bunkyo-ku, Tokyo, 113 Japan
}

\begin{abstract}
The mechanism of secretory supply of $\mathrm{K}^{+}$into the diluting segment of nephron was studied in Triturus kidneys by observing $\mathrm{Ba}^{2+}$ effects on electrical phenomena related to $\mathrm{K}^{+}$movements and other electrical properties of the segment. $\mathrm{Ba}^{2+}(1-2 \mathrm{mM})$ applied into the luminal fluid completely blocked $\mathrm{K}^{+}$movement into the lumen during the stop-flow of the intraluminal $\mathrm{K}^{+}$-free solution. Also, $\mathrm{Ba}^{2+}$ inhibited transepithelial $\mathrm{K}^{+}$diffusion potential induced by alterations in the intraluminal $\mathrm{K}^{+}$concentration and increased transtubular resistance $\left(R_{\mathrm{t}}\right)$. A rapidly decaying time course of the $\mathrm{K}^{+}$diffusion potential and its high peak amplitude (near the maximum expected from an imposed concentration difference) suggest that the diffusion potential was generated across the paracellular pathways. Step-changes in the $\mathrm{Na}^{+}$concentration induced similar but smaller diffusion potentials, which were also inhibited by $\mathrm{Ba}^{2+}$. Replacement of $\mathrm{Cl}^{-}$with $\mathrm{SO}_{4}{ }^{2-}$ converted the time courses of both $\mathrm{K}^{+}$and $\mathrm{Na}^{+}$diffusion potentials to a sustained type. These suggest that the pathway has a specially high permeability to $\mathrm{K}^{+}$and lower permeabilities to $\mathrm{Na}^{+}$and $\mathrm{Cl}^{-}$. Triaminopyrimidine and kinetin similarly blocked $\mathrm{K}^{+}$movement during stop-flow of a $\mathrm{K}^{+}$-free solution. The low $R_{\mathrm{t}}$, a unique property of the segment, could be ascribed to the leakiness of the paracellular pathway from the comparison of input resistances of cells and cell surface areas between this segment and the proximal tubule. Based on these findings and other reported data, a novel mechanism of $\mathrm{K}^{+}$supply was proposed which assumed the presence of a local pool of a high $\mathrm{K}^{+}$concentration in the paracellular pathway and secretory movement of $\mathrm{K}^{+}$through intercellular junctional complexes.
\end{abstract}

Key words: $\mathrm{Ba}^{2+}$ effect, secretory $\mathrm{K}^{+}$movement, electrical properties, paracellular cation conductance, early distal tubule (Triturus kidney).

Received for publication May 18, 1985

* Present adderss: Department of Medicine, Kitasato University School of Medicine, Sagamihara, Kanagawa, 228 Japan 
It has been established that the rate-limiting step of active transport of $\mathrm{Cl}^{-}$ (and $\mathrm{Na}^{+}$) by the diluting segment of nephron (amphibian early distal tubule and mammalian thick ascending limb of Henle's loop) is the $2 \mathrm{Cl}^{-} / \mathrm{Na}^{+} / \mathrm{K}^{+}$cotransport across the luminal membrane (GREGER et al., 1983; GREGER and SCHLATTER, 1984; HoSHi et al., 1984; KöNING et al., 1983; OBERLEITHNER et al., 1982, 1983a). Because of much lower concentrations of $\mathrm{K}^{+}$than $\mathrm{Na}^{+}$and $\mathrm{Cl}^{-}$concentrations of luminal fluid of this segment (OBERLeitHNer et al., 1983a; TeUlon et al., 1985), activity of the cotransport mechanism with such a stoichiometry will cause a rapid depletion of $\mathrm{K}^{+}$in the luminal fluid, thereby immediately inhibiting the coupled ion transport if the secretory supply of $\mathrm{K}^{+}$is absent. Accordingly, a sufficient and continuous supply of $\mathrm{K}^{+}$into the luminal fluid is essential for proper operation of the cotransport process and transepithelial $\mathrm{NaCl}$ transport. Some authors have demonstrated the presence of luminal membrane $\mathrm{K}^{+}$permeability and an electrochemical driving force for $\mathrm{K}^{+}$favorable to drive $\mathrm{K}^{+}$from inside the cells to the lumen across the luminal membrane in both mammalian (GREGER and SCHLATTER, 1983) and amphibian (GugGino et al., 1982) diluting segments. These authors suppose that $\mathrm{K}^{+}$is recycling across the luminal membrane through the cotransporter and the conductive pathway for $\mathrm{K}^{+}$present in the same membrane. However, substantial evidence supporting this type of $\mathrm{K}^{+}$recirculation has not yet been demonstrated experimentally. Moreover, although the role of the paracellular pathway in the secretory supply of $\mathrm{K}^{+}$is largely unknown, a favorable blood to lumen $\mathrm{K}^{+}$electrochemical gradient is reported to be present under in vivo experimental conditions (TEULON et al., 1985).

$\mathrm{Ba}^{2+}$ has been known to block $\mathrm{K}^{+}$conductance of the luminal membranes of renal tubules including the diluting segment (BIAGI et al., 1981; GREGER and Schlatter, 1983; Guggino et al., 1982; O'NeIL, 1983). This divalent cation is also known to interfere with selective cation conductance of the paracellular pathways of leaky epithelia (WRIGHT and DiAmOND, 1968). Therefore, it may be anticipated that introduction of $\mathrm{Ba}^{2+}$ into the lumen would effectively block the secretory movements of $\mathrm{K}^{+}$. The aim of the present study was to assess electrical phenomena directly related to the secretory $\mathrm{K}^{+}$supply into the lumen of the diluting segment and the effect of $\mathrm{Ba}^{2+}$ on them. Attempts have also been made to characterize the $\mathrm{Ba}^{2+}$ effects on other electrical properties of these particular segments in order to understand the mode of action of $\mathrm{Ba}^{2+}$.

\section{MATERIALS AND METHODS}

Preparation of isolated kidney. Isolated pelvic kindeys of male newts (Triturus pyrrhogaster) were used in all experiments. The animals were purchased from a local animal dealer and kept in cold tap water $\left(10-15^{\circ} \mathrm{C}\right)$ without feeding for a few months. After decapitation, the kidneys were carefully removed from the body after dissecting surrounding connective tissue. An isolated unilateral 
kidney, weighing 40-50 mg, was fixed with fine needles on a paraffin block attached to the bottom of a lucite chamber. The kidney was fixed with its medial side upward, since the early distal tubules are mainly located on this side, forming loosely entangled loops (HosHI et al., 1981b). The chamber was continuously perfused with a fresh oxygenated standard or a modified Ringer's solution, depending on the purpose of the experiment. The flow rate was set at about $3 \mathrm{ml} / \mathrm{min}$, and the temperature of the solution was maintained at $25 \pm 1^{\circ} \mathrm{C}$. Under such in vitro conditions, all superficial early distal tubules exhibited a stable lumen-positive transtubular potential difference $\left(V_{t}\right)$ at least $3 \mathrm{~h}$ after fixation of the preparation in the chamber when perfused with the standard Ringer's solution (HosHI et al., 1981b).

Microperfusion of the early distal tubule. One of the Bowman's capsules was punctured by means of a glass capillary micropipette filled with the standard Ringer's solution which was colored with $0.05 \%$ Fast-green FCF. Injection of the colored solution visualized a single nephron. Then two other microperfusion pipettes, one filled with a test solution and the other with a control solution containing no dye, were inserted into the same Bowman's capsule. Intraluminal perfusion was performed by applying pressure of $20-50 \mathrm{mmHg}$ to the pipettes, depending on their resistance to flow. The intraluminal perfusion was carried out at relatively high flow rates, $15-35 \mathrm{nl} / \mathrm{min}$, in order to obtain the desired ionic composition at the site of investigation as tested in a previous study (HosHI et al., 1983). All pipettes were beveled at a tip diameter of $10 \mu \mathrm{m}$. The standard Ringer's solution used had the following composition (in $\mathrm{mM}$ ): $\mathrm{NaCl}: 105 ; \mathrm{KCl}$ : 2.5; $\mathrm{CaCl}_{2}: 1.8 ; \mathrm{MgCl}_{2}: 1.0 ;$ D-glucose: 5.5, and Tris/HEPES: 10.0 (pH 7.4). The solution was equilibrated with $100 \% \mathrm{O}_{2}$. $\mathrm{Na}^{+}$-free solutions were prepared by replacing $\mathrm{NaCl}$ with Tris chloride without changing other constituents. Usually, phosphate was omitted because of frequent tests of the effects of $\mathrm{Ba}^{2+}$, which formed insoluble salt with phosphate. Omission of phosphate did not cause any detectable effects on the control values of $V_{t}$ and viability of the preparations.

Electrical measurements. The transtubular potential $\left(V_{\mathrm{t}}\right)$ and the transmembrane potential across the basolateral membrane $\left(V_{\mathrm{b}}\right)$ were recorded with conventional Ling-Gerard-type microelectrodes. The fiber-built-in-type Pyrex glass tubings ( $1.1 \mathrm{~mm}$ o.d., $0.6 \mathrm{~mm}$ i.d., and $9 \mathrm{~cm}$ length) were pulled by means of a microelectrode puller (Narishige type-PC80), and the capillaries were backfilled with $3 \mathrm{M} \mathrm{KCl}$. Their electrical resistance was in the range of $10-20 \mathrm{M} \Omega$, and tip potentials were less than $5 \mathrm{mV}$. The transtubular resistance $\left(R_{\mathrm{t}}\right)$ was measured by simple cable analysis. Rectangular current pulses of constant intensity $(1.5 \times$ $\left.10^{-7} \mathrm{~A}\right)$ were injected into the lumen through a microelectrode and the resulting voltage deflections were recorded with another intraluminal microelectrode at various distances from the source. Current was supplied from a constant current generator (Digitimer-Neurolog system NL-800). The equivalent short circuit current $\left(I_{\mathrm{sc}}\right)$ was calculated from the values of $V_{\mathrm{t}}$ and $R_{\mathrm{t}}$ obtained in single tubules, 
as described by MACKNIGHT et al. (1980). In some nephrons, the input resistance of the cytoplasmic core was measured in both the diluting segment and the proximal tubule. The tubular cells were impaled with a microelectrode and current pulses of $0.2 \mathrm{nA}$ were injected through the same electrode. Current clamp techniques and a patch clamp amplifier (List-Medical EPC-7) were employed for this purpose. From voltage deflections recorded by the same microelectrode and from current passed, the input resistance was calculated after subtraction of the electrode resistance.

Morphometric observations. In order to know cell surface areas for both the diluting segment and the proximal tubule, the outlines of these tubular cells were measured on histological preparations which were fixed and stained as follows. Small blocks of excised kidneys were fixed in $2.5 \%$ glutaraldehyde for $2 \mathrm{~h}$ and postfixed in $1 \%$ osmium tetroxide for $2 \mathrm{~h}$. After dehydration in graded ethanols, they were embedded in Epon 812. One $\mu \mathrm{m}$ thick sections were made by use of a microtome and stained with toluidine blue. Microscopic photographs of tubules were taken and printed. The margin of the tubular cells was traced on tracing paper, and the length of the margins of single cells and the total surface areas were measured automatically by a digitizer (9874A, Hewlett Packard) linked to a computer (HP-1000, Hewlett Packard). In computation of the total surface area, cell shape was assumed to be trapezoid and the thickness of cells at the apical and basal portions was assumed to be the same as the with of the apical side.

\section{RESULTS}

\section{Effect of $\mathrm{Ba}^{2+}$ on secretory $\mathrm{K}^{+}$movement}

To assess the mechanisms of $\mathrm{K}^{+}$entry in the lumen and the effect of $\mathrm{Ba}^{2+}$ on it, the following experiments were performed. First, the lumen of an early distal tubule and the bath were perfused with a control sulution containing $2.5 \mathrm{mM} \mathrm{KCl}$, $5 \mathrm{~mm} \mathrm{NaCl}$, and $90 \mathrm{~mm}$ Tris- $\mathrm{Cl}$; then the luminal perfusate was switched to a $\mathrm{K}^{+}$free solution without changing other ionic concentrations. Thereafter, the luminal perfusion was stopped for a few min. $V_{t}$ was continuously recorded throughout these perfusion changes. As demonstrated in a previous paper (HosHi et al., 1983), a lumen-positive $V_{\mathrm{t}}$ of about $25 \mathrm{mV}$ was consistently recorded during control perfusion. The lumen-positive $V_{\mathrm{t}}$ rapidly decreased and eventually stabilized around $0 \mathrm{mV}$, when a $\mathrm{K}^{+}$-free solution was introduced in the lumen of the tubule.

When the $\mathrm{K}^{+}$-free perfusion was stopped, $V_{\mathrm{t}}$ immediately began to rise spontaneously (Fig. 1A). The initial rate of change in $V_{\mathrm{t}}$ was $8.7 \pm 0.9 \mathrm{mV} / 30 \mathrm{~s}(n=$ 7). The rate of $V_{t}$ increase slowed down with time. However, if luminal stopflow conditions were prolonged, $V_{\mathrm{t}}$ eventually reached a fairly high level, near the control $V_{t}$ value. Flushing the lumen with the $\mathrm{K}^{+}$-free solution caused an immediate drop and stabilization of $V_{\mathrm{t}}$ again around $0 \mathrm{mV}$. Switching the luminal perfusate back to the control solution restored $V_{t}$ to control levels (Fig. 1A). Such 
A

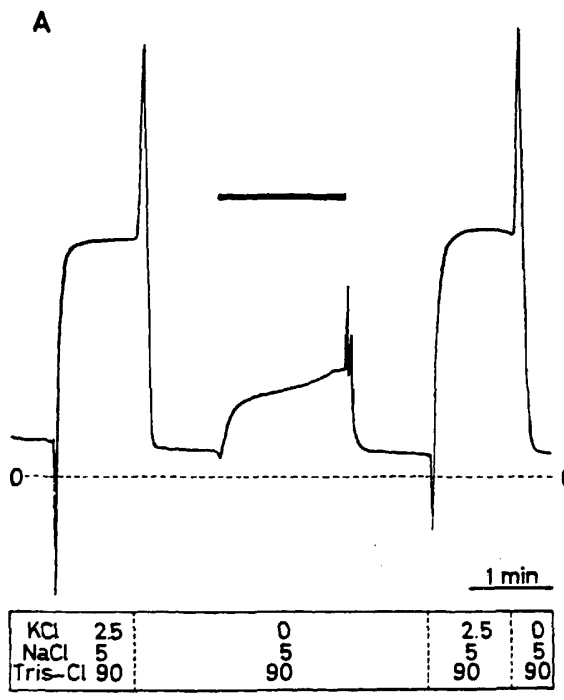

B

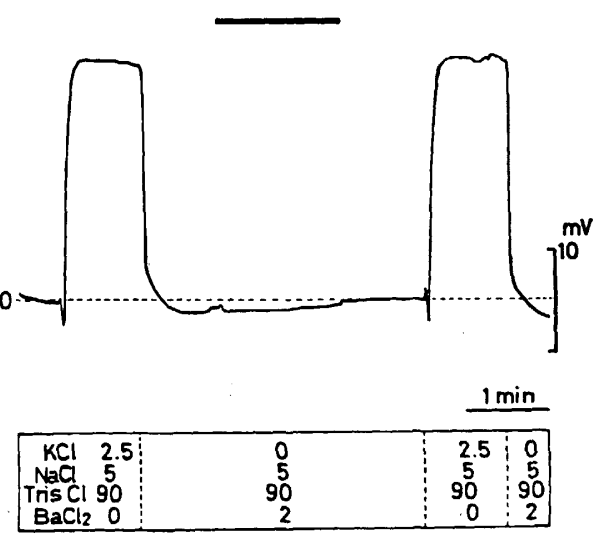

Fig. 1. Changes in the transtubular potential difference $\left(V_{t}\right)$ of the early distal tubule induced by changing the intraluminal perfusion solution from a control to a $\mathrm{K}^{+}$-free solution and cessation of flow of a $\mathrm{K}^{+}$-free perfusion solution. Intraluminal $\mathrm{K}^{+}$-free solution was $\mathrm{Ba}^{2+}$-free in $\mathrm{A}$ (control), and it contained $2 \mathrm{mM} \mathrm{Ba}^{2+}$ in $\mathrm{B}$. Heavy horizontal lines indicate the period of stoppage of intraluminal perfusion. Upward shift of voltage from zero line indicates the increase in positivity of the luminal side. Concentrations of main constituents of the luminal perfusion solutions are given at the bottom of each trace in mM.

responses were observed in all tubules examined. The addition of furosemide $\left(2 \times 10^{-5} \mathrm{M}\right)$ to the $\mathrm{K}^{+}$-free solution completely suppressed the spontaneous rise of $V_{\mathrm{t}}$ during stop-flow. Also, the omission of $\mathrm{Na}^{+}$or $\mathrm{Cl}^{-}$from the perfusion solutions resulted in the failure of the spontaneous rise of $V_{\mathrm{t}}$. These findings indicate that the spontaneous $V_{\mathrm{t}}$ rise during stop-flow is an expression of the reactivation of the $2 \mathrm{Cl}^{-} / \mathrm{Na}^{+} / \mathrm{K}^{+}$cotransport which generates a lumen-positive $V_{\mathrm{t}}$. This reactivation is obviously due to the entry of $\mathrm{K}^{+}$into the lumen, i.e. a gradual increase of intraluminal $\mathrm{K}^{+}$concentration.

When 1-2 $\mathrm{mM} \mathrm{Ba}^{2+}$ was added to the $\mathrm{K}^{+}$-free solution, spontaneous generation of the lumen-positive $V_{\mathrm{t}}$ during the stop-flow was completely suppressed as shown in Fig. 1B. Such a remarkable effect of $\mathrm{Ba}^{2+}$ can be interpreted as the result of its blocking action on $\mathrm{K}^{+}$movement into the lumen. The $\mathrm{Ba}^{2+}$ effect rules out the possibility that spontaneous $V_{\mathrm{t}}$ rise results from leakage of $\mathrm{K}^{+}$from a $V_{\mathrm{t}}$-recording microelectrode.

$\mathrm{Ba}^{2+}$ had another important effect. In the absence of $\mathrm{Ba}^{2+}$, spiky $V_{\mathrm{t}}$ changes always occurred when the intraluminal $\mathrm{K}^{+}$concentration was changed. Addition of $\mathrm{Ba}^{2+}$ to the $\mathrm{K}^{+}$-free solution abolished these spiky $V_{\mathrm{t}}$ changes as well as spontaneous gradual increases of $V_{t}$, which was observed during stop-flow in the absence of $\mathrm{Ba}^{2+}$. The spiky $V_{\mathrm{t}}$ changes can be regarded as $\mathrm{K}^{+}$diffusion potentials 
A

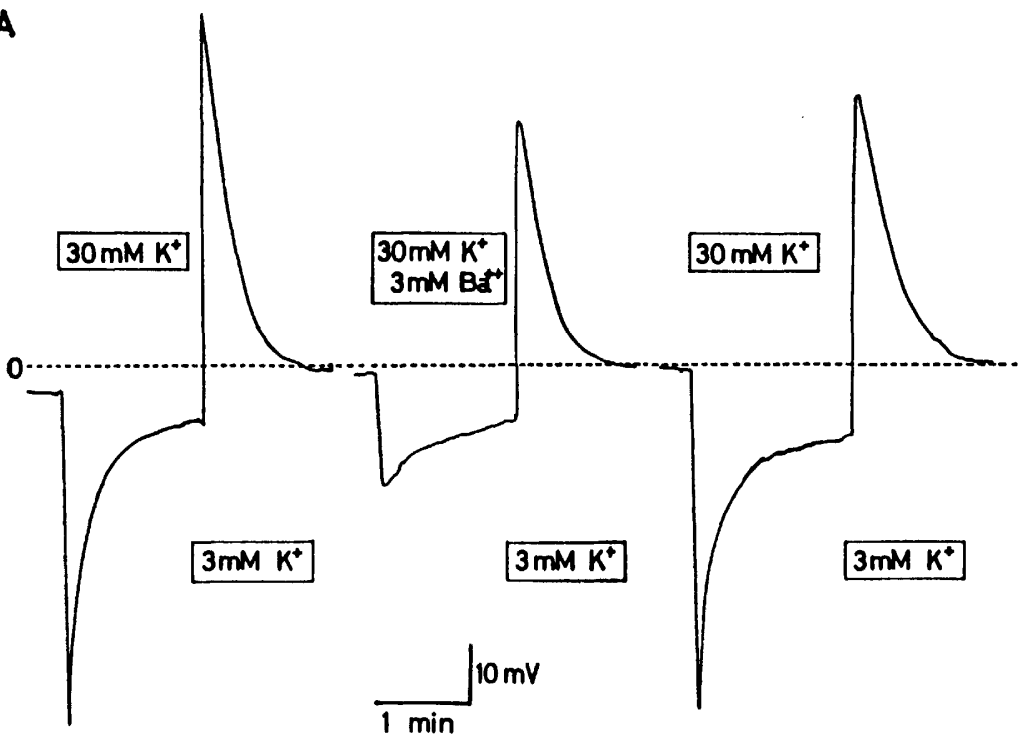

B

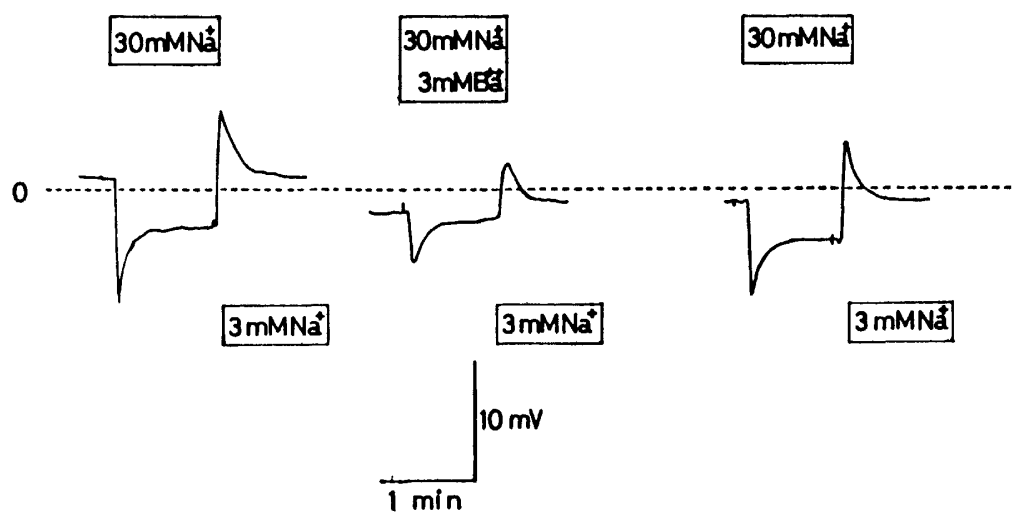

Fig. 2. $\mathrm{K}^{+}(\mathrm{A})$ and $\mathrm{Na}^{+}(\mathrm{B})$ diffusion potentials across the tubular wall induced by 10 -fold changes ( 3 to $30 \mathrm{~mm}$ or vice versa) in intraluminal concentrations of respective cations. In $\mathrm{A}, \mathrm{Na}^{+}$was totally replaced with Tris in order to suppress the luminal membrane tripleion cotransport process. $\mathrm{Ba}^{2+}$ effect was observed by adding $\mathrm{Ba}^{2+}$ at 3 to a $30 \mathrm{mM} \mathrm{K}^{+}$ solution (middle trace). In $\mathrm{B}, V_{\mathrm{t}}$ changes were recorded in the presence of $10^{-5} \mathrm{M}$ furosemide. The middle trace shows the effect of $\mathrm{Ba}^{2+}$ added to a $30 \mathrm{mM} \mathrm{Na}{ }^{+}$luminal perfusion solution.

since only the intraluminal $\mathrm{K}^{+}$concentration was changed in this series of experiments, and the direction of $V_{\mathrm{t}}$ changes was consistent with anticipated $\mathrm{K}^{+}$movements along an imposed $\mathrm{K}^{+}$concentration gradient across the tubule. The rapidly decaying time course (spiky shape), large peak amplitude and high sensitivity of this transient to $\mathrm{Ba}^{2+}$ suggest some action of $\mathrm{Ba}^{2+}$ on diffusional pathways of $\mathrm{K}^{+}$. 

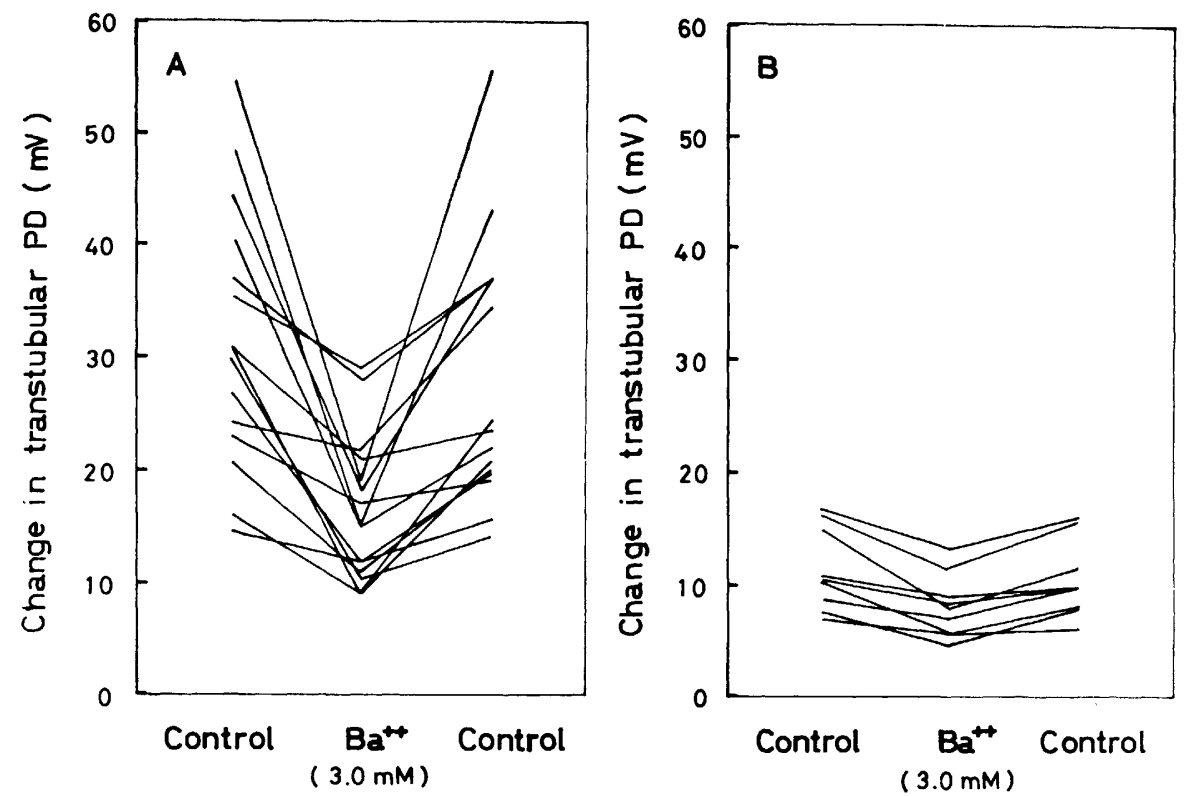

Fig. 3. Summarized data of $\mathrm{Ba}^{2+}$ effects on $\mathrm{K}^{+}$diffusion potential (A) and $\mathrm{Na}^{+}$diffusion potential (B). The diffusion potentials were generated by a 10 -fold change in intraluminal concentrations of $\mathrm{K}^{+}$or $\mathrm{Na}^{+}$and the peak amplitude was measured. $\mathrm{Ba}^{2+}$ effects were observed by adding $\mathrm{Ba}^{2+}(3 \mathrm{mM})$ to $30 \mathrm{~mm} \mathrm{~K} \mathrm{~K}^{+}$or $30 \mathrm{mM} \mathrm{Na}^{+}$luminal perfusion solutions.

Accordingly, characteristics of $\mathrm{K}^{+}$diffusion potential were further studied.

Transepithelial $\mathrm{K}^{+}$and $\mathrm{Na}^{+}$diffusion potentials and their sensitivity to $\mathrm{Ba}^{2+}$

Transepithelial diffusion potentials of $\mathrm{K}^{+}$were generated by 10 -fold stepchanges in the luminal $\mathrm{K}^{+}$concentration (from 3 to $30 \mathrm{mM}$ or vice versa) in the absence of any activity of the $2 \mathrm{Cl}^{-} / \mathrm{Na}^{+} / \mathrm{K}^{+}$cotransport mechanism. The activity of the cotransport was suppressed by eliminating $\mathrm{Na}^{+}$from the perfusion solutions or by adding $10^{-5} \mathrm{M}$ furosemide, a potent inhibitor of the cotransport, in the luminal fluid. Under such conditions, $V_{t}$ remained around $0 \mathrm{mV}$, as shown in a previous paper (HosHi et al., 1983).

As shown in Fig. 2, changes in luminal $\mathrm{K}^{+}$concentrations at constant osmolality resulted in large spiky $V_{\mathrm{t}}$ changes. The amplitude of the $V_{\mathrm{t}}$ change frequently exceeded $50 \mathrm{mV}$ when exchange of the perfusate was rapid enough. The changes were entirely symmetric when the direction of the concentration change was reversed. Addition of $\mathrm{Ba}^{2+}$ to $30 \mathrm{mM} \mathrm{K} \mathrm{K}^{+}$solution greatly reduced the amplitude of the $V_{\mathrm{t}}$ change induced by introduction of $30 \mathrm{mM} \mathrm{K} \mathrm{K}^{+}$solution to the lumen. For the sake of comparison, the effects of similar step-changes of $\mathrm{Na}^{+}$concentrations were studied in the presence of furosemide. Similar but significantly smaller symmetric $V_{\mathrm{t}}$ changes were observed, and again $\mathrm{Ba}^{2+}$ reduced their magnitude. 

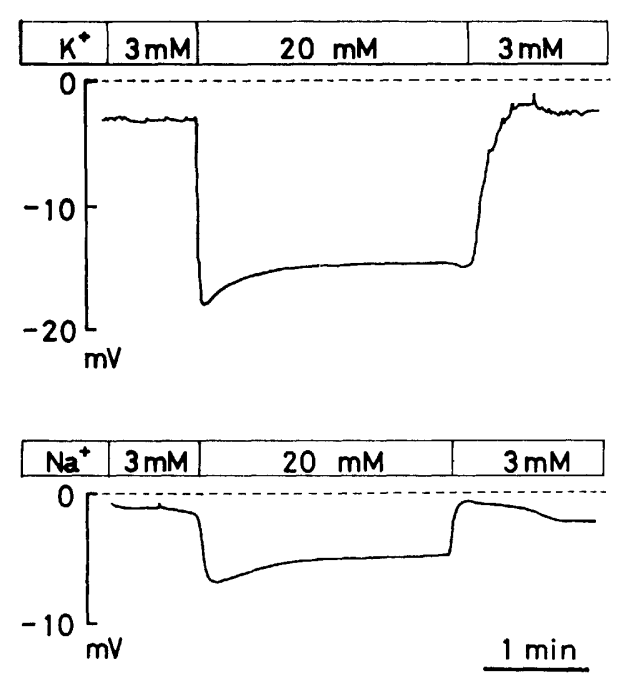

Fig. 4. Examples of $\mathrm{K}^{+}$(upper trace) and $\mathrm{Na}^{+}$(lower trace) diffusion potentials in $\mathrm{SO}_{4}{ }^{2-}$ substituted media. In this series of experiments, intraluminal concentrations of $\mathrm{K}^{+}$or $\mathrm{Na}^{+}$were changed from 3 to $20 \mathrm{~mm}$ as indicated in horizontal columns.

The data obtained from different preparations are summarized in Fig. 3, where peak amplitudes of $\mathrm{K}^{+}$and $\mathrm{Na}^{+}$diffusion potentials in the absence and presence of $\mathrm{Ba}^{2+}$ are compared. The average amplitude of $\mathrm{K}^{+}$diffusion potential in the absence of $\mathrm{Ba}^{2+}$ was $32.0 \pm 3.0 \mathrm{mV}(n=9)$; it decreased to $16.6 \pm 1.6 \mathrm{mV}$ when $3 \mathrm{mM} \mathrm{Ba}^{2+}$ was added to $30 \mathrm{~mm} \mathrm{~K}{ }^{+}$luminal perfusion fluid. The value of $\mathrm{Na}^{+}$ diffusion potential was $11.5 \pm 1.2 \mathrm{mM}(n=9)$ in the control, $8.1 \pm 1.0 \mathrm{~mm}$ in the presence of $\mathrm{Ba}^{2+}(3 \mathrm{mM})$ in a $30 \mathrm{mM} \mathrm{Na}^{+}$solution. Thus, $\mathrm{K}^{+}$diffusion potential was about 3 times larger than $\mathrm{Na}^{+}$in amplitudes, and both $\mathrm{K}^{+}$and $\mathrm{Na}^{+}$diffusion potentials were similarly sensitive to $\mathrm{Ba}^{2+}$.

Spiky shapes of both $\mathrm{K}^{+}$and $\mathrm{Na}^{+}$diffusion potentials suggest that these potentials are generated across a common barrier also permeable to anions $\left(\mathrm{Cl}^{-}\right)$, since permeable anions exert a shunting effect. To ascertain this, similar stepchanges in $\mathrm{K}^{+}$and $\mathrm{Na}^{+}$concentrations were examined in the absence of $\mathrm{Cl}^{-}, \mathrm{SO}_{4}{ }^{2-}$ being the principal anion in both intra- and peritubular fluids. As shown in Fig. 4 , the shapes of diffusion potentials were altered to a well-type (or square-wave type) by $\mathrm{SO}_{4}{ }^{2-}$ replacement, confirming the shunting effect of $\mathrm{Cl}^{-}$. In this series of experiments, $\mathrm{K}^{+}$and $\mathrm{Na}^{+}$concentrations were changed from 3 to $20 \mathrm{mM}$ or vice versa. The peak amplitude of the diffusion potential was $16.6 \pm 1.7 \mathrm{mV}(n=7)$ for $\mathrm{K}^{+}$and $7.2 \pm 1.7 \mathrm{mV}(n=8)$ for $\mathrm{Na}^{+}$. These observations indicate that the pathway across which diffusion potentials are generated is permeable not only to $\mathrm{K}^{+}$and $\mathrm{Na}^{+}$but also to $\mathrm{Cl}^{-}$. This pathway displays higher permeability to $\mathrm{K}^{+}$ than $\mathrm{Na}^{+}$, as evidenced by about 3 times as large an amplitude of $\mathrm{K}^{+}$diffusion potentials. Furthermore, the amplitude of $\mathrm{K}^{+}$diffusion potential was frequently 
A

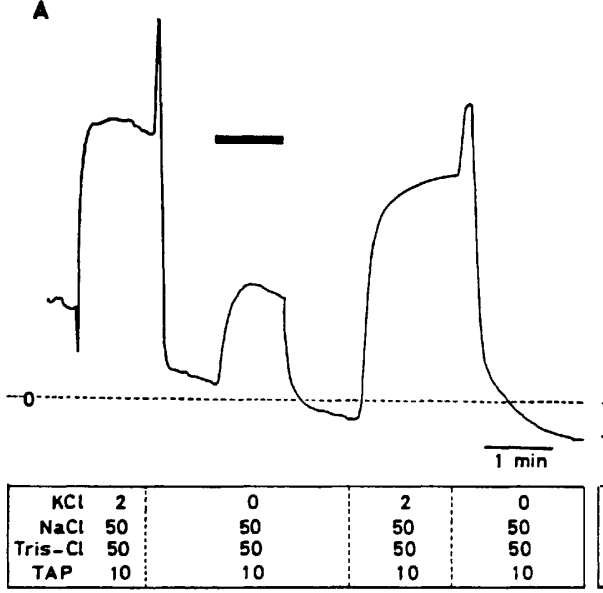

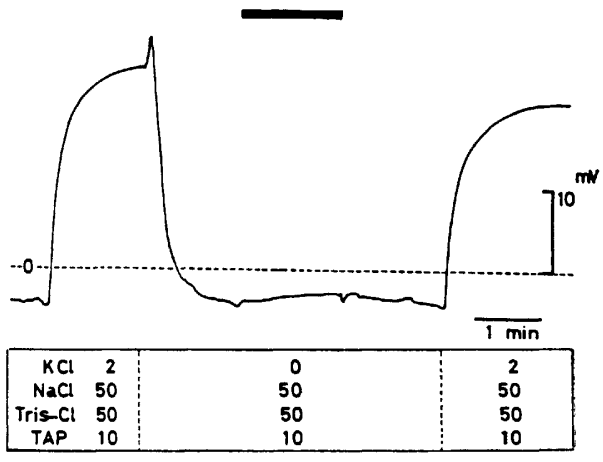

Fig. 5. Effects of 2,4,6-triaminopyrimidine (TAP) on spontaneous $V_{t}$ increase during stopped-perfusion with a $\mathrm{K}^{+}$-free solution. TAP was added to all luminal perfusion solutions at $10 \mathrm{mM}$. A: immediately after the start of exposure to $10 \mathrm{~mm}$ TAP (virtually no change was observed as compared with the control). B: 30 min after the start of exposure. The sequence of alterations of perfusion was the same as in Fig. 1.

close to the $\mathrm{K}^{+}$equilibrium potential $\left(56 \mathrm{mV}\right.$ at $\left.25^{\circ} \mathrm{C}\right)$. These observations strongly suggest that transepithelial diffusion potentials are probably generated at the paracellular pathway, not at the luminal membrane.

Effects of triaminopyrimidine $(T A P)$ and kinetin on $V_{\mathrm{t}}$ increase during $\mathrm{K}^{+}$-free stopped-perfusion

It is apparent from the above that $\mathrm{Ba}^{2+}$ blocks the cation permeability of the pathway across which $\mathrm{K}^{+}$and $\mathrm{Na}^{+}$diffusion potentials are generated. Suppression of both $\mathrm{K}^{+}$diffusion potential and the gradual increase of $V_{t}$ during stop-flow conditions suggests that $\mathrm{K}^{+}$movement during stop-flow and generation of the spiky diffusion potential occur through the same route. In an attempt to examine this possibility, the effects of other substances known to interfere with selective cation conductance of the paracellular pathway of leaky epithelia were examined. 2,4,6Triaminopyrimidine (MORENO, 1975) and kinetin, a plant cytokinin (BENTZEL et al., 1976), block the selective cation conductance of the paracellular pathways of small intestinal epithelium and the gallbladder, respectively. In the presence of $10 \mathrm{~mm}$ TAP in luminal perfusion fluids, the spontaneous generation of lumenpositive $V_{\mathrm{t}}$ during $\mathrm{K}^{+}$-free stopped-perfusion was strongly inhibited or nearly completely abolished (Fig. 5). In contrast to $\mathrm{Ba}^{2+}$, the time course of the appearance of the TAP effect was much slower, i.e. the maximum effect was observed about $30 \mathrm{~min}$ after the start of exposure to the drug. Similar slow development of the TAP effect has been noticed in the gallbladder and small intestine (MORENO, 1975). For this reason, TAP was added to both the control and $\mathrm{K}^{+}$-free solutions 
Table 1. Electrical parameters of the early distal tubule of the Triturus kidney.

\begin{tabular}{cccccc}
\hline$V_{\mathrm{t}}(\mathrm{mV})$ & $V_{\mathrm{b}}(\mathrm{mV})$ & $V_{\mathrm{a}}(\mathrm{mV})$ & $R_{\mathrm{t}}\left(\Omega \cdot \mathrm{cm}^{2}\right)$ & $\begin{array}{c}\text { Eq. } I_{\mathrm{sc}} \\
\left(\mathrm{mA} / \mathrm{cm}^{2}\right)\end{array}$ & $\begin{array}{c}\text { Input } \\
\text { resistance } \\
(\mathrm{M} \Omega)\end{array}$ \\
\hline$+\begin{array}{c}13.7 \pm 1.0 \\
(n=35)\end{array}$ & $\begin{array}{c}-70.6 \pm 2.0 \\
(n=29)\end{array}$ & -84.3 & $\begin{array}{c}31.0 \pm 0.9 \\
(n=22)\end{array}$ & 0.44 & $\begin{array}{c}17.5 \pm 4.2 \\
(n=4)\end{array}$ \\
\hline
\end{tabular}

All measurements were performed in nephrons which were perfused with the standard Ringer's solution on both sides. $V_{t}$ : the transtubular potential with reference to the peritubular fluid, $V_{\mathrm{b}}$ : the peritubular membrane potential with reference to the peritubular fluid, $V_{\mathrm{a}}$ : the luminal membrane potential with reference to the luminal fluid, $R_{\mathrm{t}}$ : specific transtubular resistance, Eq. $I_{\mathrm{sc}}$ : equivalent short circuit current.

in this series of experiments. The transient (spiky) $V_{\mathrm{t}}$ changes induced by changes in intraluminal $\mathrm{K}^{+}$concentrations were also depressed by TAP, though its inhibitory effect was significantly weaker than $\mathrm{Ba}^{2+}$.

Kinetin added to the luminal perfusion fluid was found to exert a weak but similar inhibitory effect on the spontaneous $V_{\mathrm{t}}$ increase during $K^{+}$-free stoppedperfusion. After 20 to $25 \mathrm{~min}$ exposure to $1 \mathrm{~mm}$ kinetin, the initial velocity of $V_{\mathrm{t}}$ increase decreased to about $40 \%$ of the controls, i.e. the initial rate decreased from 10 to $4.2 \mathrm{mV} / \mathrm{min}$ (an average of two experiments). The effect of kinetin appeared slightly faster than that of TAP, the maximum effect being observed $10 \mathrm{~min}$ after the start of exposure.

\section{Effects of $\mathrm{Ba}^{2+}$ on some electrical parameters}

The values of various electrical parameters of Triturus early distal tubule estimated in the present study are listed in Table 1. Under the conditions of perfusion with a standard Ringer's solution, $V_{\mathrm{t}}$ was $+13.7 \pm 1.0 \mathrm{mV}$, lumen-positive, the value being similar to those previously reported in amphibian diluting segments (Stoner, 1977; Hoshi et al., 1981b, Teulon and Anagnostopoulos, 1982). The transmembrane potential across the basolateral membrane $\left(V_{\mathrm{b}}\right)$ was $70.6 \pm 2.0 \mathrm{mV}$. The apical transmembrane potential $\left(V_{\mathrm{a}}\right)$ was, therefore, $84.3 \mathrm{mV}$. The $V_{\mathrm{b}}$ was hyperpolarized when $2 \times 10^{-5} \mathrm{M}$ furosemide was applied to the lumen, the average value of $V_{\mathrm{b}}$ under such conditions being $83.4 \pm 3.8 \mathrm{mV}(n=8)$. Similar effects of furosemide were observed by OBERLEITHNER et al. (1983a). The specific transtubular resistance $\left(R_{\mathrm{t}}\right)$ was very low as already reported (HosHI et al., $1981 \mathrm{~b})$, the estimated value being $31.0 \pm 0.9 \Omega \cdot \mathrm{cm}^{2}$. The value is about one fifth that of the proximal tubule of the same animal $\left(160 \Omega \cdot \mathrm{cm}^{2}\right.$, HosH et al., 1981a). The equivalent $I_{\text {sc }}$ was, therefore, $0.44 \mathrm{~mA} / \mathrm{cm}^{2}$, the value being about 18 times higher than that in the proximal tubule.

The low value of $R_{\mathrm{t}}$ is quite characteristic of this nephron segment. To obtain some information on the relative magnitude of the various resistive barriers of the distal epithelial layer, the input resistance of the cytoplasmic core was measured and compared with that of the proximal tubule; in the latter the resistance components of the cell layer have been well analyzed quantitatively (HosHI et al., 


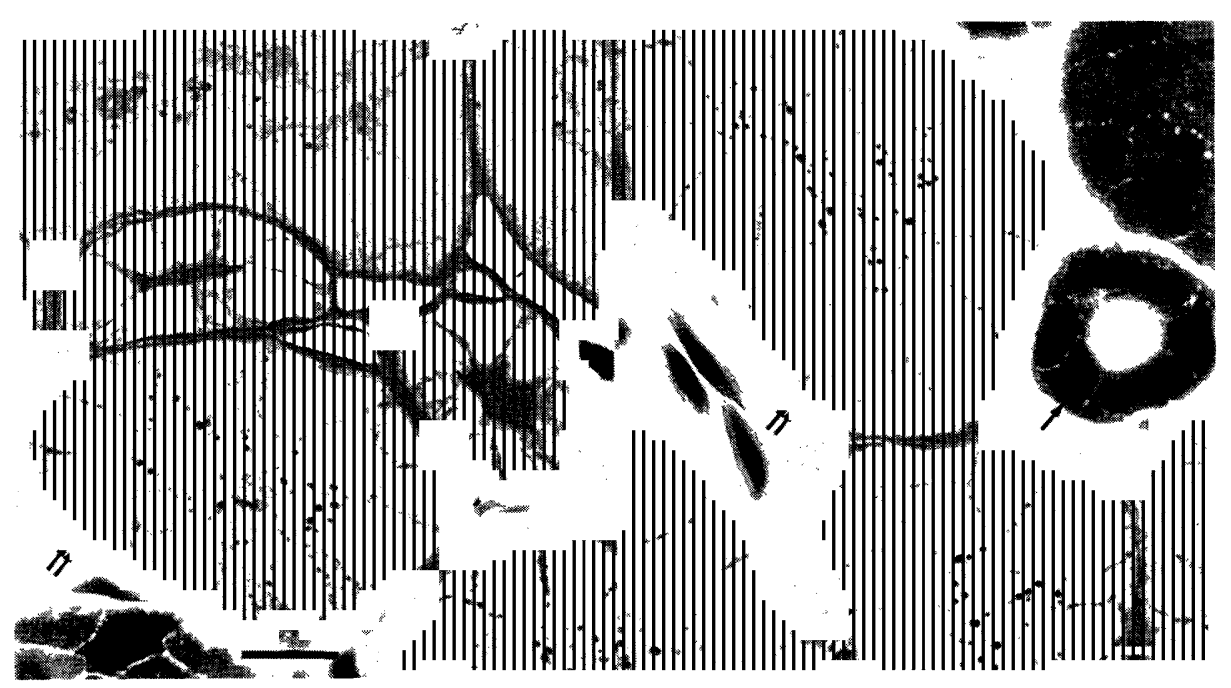

Fig. 6. Examples of microscopic photographs showing cross-sectional cell contours of the early distal tubule (single arrow) and the proximal tubule (double-arrow) of Triturus kidney. Heavy horizontal lines indicate $20 \mu \mathrm{m}$. Estimation of total surface areas of these cells (for method see METHODS) gave a mean value of $1.85 \pm 0.12 \times 10^{3} \mu \mathrm{m}^{2}$ for the proximal tubule and $0.61 \pm 0.05 \times 10^{3} \mu \mathrm{m}^{2}$ for the early distal tubule, respectively.

1981a). The average value of the input resistance in the early distal tubule was $17.5 \pm 4.2 \mathrm{M} \Omega$, against $3.0 \pm 0.3 \mathrm{M} \Omega$ in the proximal tubule. Thus, the input resistance of the early distal tubule was 5.8 times higher than that of the proximal tubule. Morphometric studies of cells of these two segments revealed that the apparent surface area of cells of the early distal tubule was about one third that of the proximal tubule (see Fig. 6 and its legend). Although there are some unresolved problems regarding the relationship between cell surface area and input resistance, it can be said that the cell membrane resistances of the early distal tubule are not much different from or not considerably less than those of the proximal tubule (2,000-3,000 $\Omega \cdot \mathrm{cm}^{2}$, HosHI et al., 1981a). Accordingly, it is difficult to ascribe the low $R_{\mathrm{t}}$ of this segment to the resistances of the cell membranes. Rather, the low $R_{\mathrm{t}}$ must be ascribed to the leakiness of the paracellular pathway.

Addition of $\mathrm{Ba}^{2+}$ to the luminal solution increased $R_{\mathrm{t}}$ in a dose-dependent way. The increase reached $170 \%$ of the controls when the $\mathrm{Ba}^{2+}$ concentration was raised to $5 \mathrm{~mm}$ (Fig. 7). In view of the low value of $R_{\mathrm{t}}$ compared to that of the membrane resistances deduced from the above comparison, this $\mathrm{Ba}^{2+}$-induced increase in $R_{\mathrm{t}}$ is thought to be mainly due to an increase in the resistance of the paracellular pathway. The $V_{\mathrm{t}}$ was also found to be sensitive to $\mathrm{Ba}^{2+}$. However, the lowering of $V_{\mathrm{t}}$ by $\mathrm{Ba}^{2+}$ was seen only when the cotransport activity was sustained, and the lumen was positive. In the presence of furosemide, introduction of $\mathrm{Ba}^{2+}$ into the lumen resulted in no change in $V_{\mathrm{t}}$ (Fig. 8). The absence of the $\mathrm{Ba}^{2+}$ effect on $V_{\mathrm{t}}$ was also seen in $\mathrm{Na}^{+}$-free conditions. Due to the depressing 


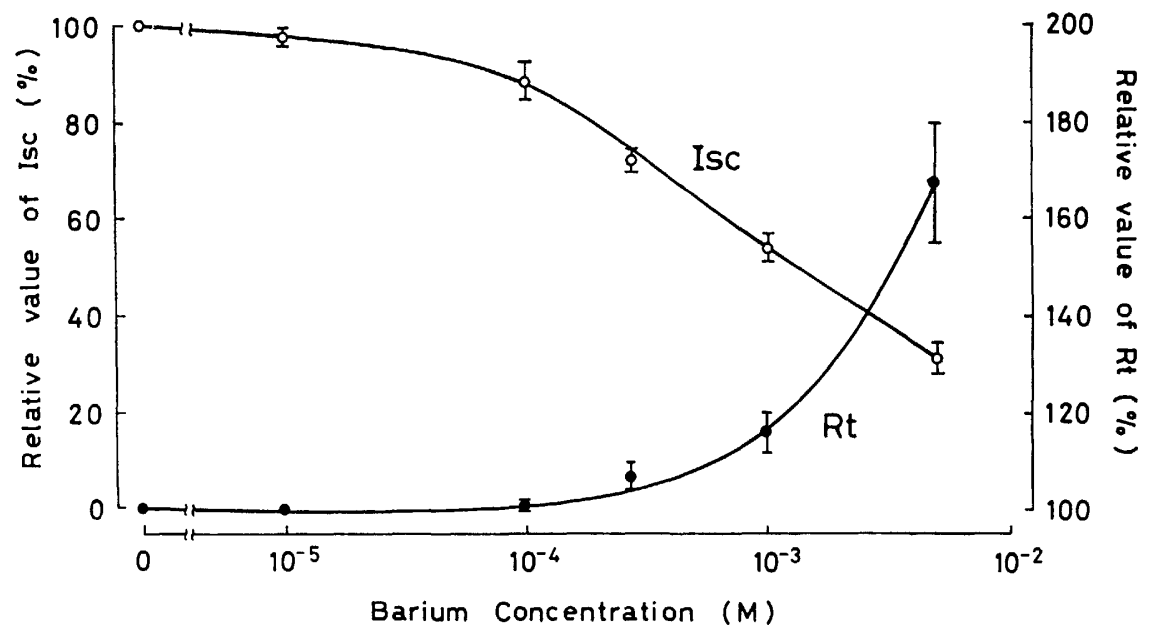

Fig. 7. Effects of $\mathrm{Ba}^{2+}$ on $R_{\mathrm{t}}$ and $I_{\mathrm{sc}}$ across the early distal tubule. Dose-dependence of effects of $\mathrm{Ba}^{2+}$ added to the intraluminal perfusion solution. Changes in both $R_{\mathrm{t}}$ and $I_{\mathrm{sc}}$ are given in relative value as per cent of the control values $\left(R_{\mathrm{t}}=31.0 \Omega \cdot \mathrm{cm}^{2}, I_{\mathrm{sc}}=\right.$ $\left.0.44 \mathrm{~mA} / \mathrm{cm}^{2}\right)$.

effect of $\mathrm{Ba}^{2+}$ on $V_{\mathrm{t}}$ and its blocking effect on transtubular conductance, $I_{\mathrm{sc}}$ was inhibited by $\mathrm{Ba}^{2+}$ dose-dependently. The decrease of $I_{\text {sc }}$ appeared as a mirror image of the increase of $R_{\mathrm{t}}$, when the data were plotted against $\mathrm{Ba}^{2+}$ concentration (Fig. 7).

\section{DISCUSSION}

In the present study, intraluminally applied $\mathrm{Ba}^{2+}$ was found to completely block $\mathrm{K}^{+}$movement from peritubular fluid or inside the tubular cells to the lumen of the early distal tubule, when this movement was artificially instituted by stoppedperfusion with a $\mathrm{K}^{+}$-free solution. Under such experimental conditions, a secretory driving force for $\mathrm{K}^{+}$was present across both the luminal membrane and the tubular wall, so that $\mathrm{K}^{+}$might move via two possible routes, the luminal membrane or the paracellular pathway. Two major findings obtained in the present study point to the dominant role of the latter for $\mathrm{K}^{+}$movement under such conditions. One is that the transepithelial $\mathrm{K}^{+}$diffusion potential induced by changes in the intraluminal $\mathrm{K}^{+}$concentration is strongly suppressed by $\mathrm{Ba}^{2+}$, concomitantly with the suppression of the electrical phenomenon which is directly related to $\mathrm{K}^{+}$supply into the lumen, which is the spontaneous gradual increase in $V_{\mathrm{t}}$ during the stop-flow. $\mathrm{K}^{+}$diffusion potential observed in this nephron segment by rapid changes in intraluminal $\mathrm{K}^{+}$concentrations had a rapidly decaying time course (spiky shape) and a very large amplitude approaching the equilibrium potential of $\mathrm{K}^{+}$, as expected from the imposed $\mathrm{K}^{+}$concentration difference. The spiky 


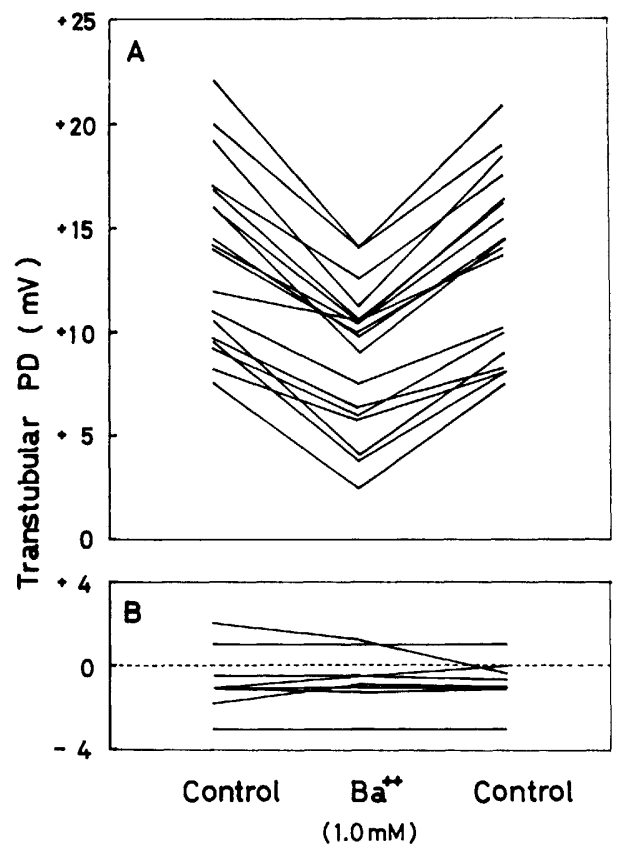

Fig. 8. Comparison of $\mathrm{Ba}^{2+}$ effects on $V_{\mathrm{t}}$ in the presence (A) and absence (B) of the $\mathrm{Na}^{+} /$ $\mathrm{K}^{+} / \mathrm{Cl}^{-}$cotransport. The standard Ringer's solution was used for both the luminal and peritubular perfusions. After recording of the control $V_{\mathrm{t}}$, the lumen was perfused with the same control solution but contained $1 \mathrm{mM} \mathrm{Ba}^{2+}$, and similar perfusion changes were repeated. In $\mathrm{B}$, furosemide was added at $10^{-5} \mathrm{M}$ to both the contol and the $\mathrm{Ba}^{2+}$-containing solutions.

time course was altered to a well-type (or square-wave type) when medium $\mathrm{Cl}^{-}$was replaced with $\mathrm{SO}_{4}{ }^{2-}$. This suggests that the rapid decay of the diffusion potential is probably due to the shunting effect of $\mathrm{Cl}^{-}$. This also suggests that the pathway across which the diffusion potential occurred should be permeable to $\mathrm{Cl}^{-}$, though its $\mathrm{Cl}^{-}$permeability is much smaller when compared to the $\mathrm{K}^{+}$permeability. The large amplitude near the maximum diffusion potential, as expected from the imposed concentration difference, suggests that the potential is generated across a barrier which has no additional high resistance barrier in series. In addition, the permeation pathway displays measurable permeability to $\mathrm{Na}^{+}$. In view of such properties of diffusion potentials, it is suggested that the probable site of generation is the paracellular pathway (or intercellular junctional region) rather than the luminal membrane.

A second set of findings relevant to this problem was the effect of TAP and kinetin. These substances, particularly TAP, effectively suppressed the spontaneous $V_{t}$ rise during stop-flow with a $\mathrm{K}^{+}$-free solution. TAP is known to block the selective cation conductance of the low-resistance paracellular pathways of the gall- 
bladder and the small intestine (MORENO, 1975). Slow development of the action of this substance noticed in the gallbladder and small intestine was also observed in the present preparations. Unfortunately, there is no information concerning the effect of TAP on $\mathrm{K}^{+}$channels of the luminal membranes of renal tubules. However, similarites in effective concentration and the time course of development of action may support the theory that this drug inhibits the cation conductance of the paracellular pathway of the early distal tubule, as it does in the gallbladder and small intestine (MORENO, 1975).

The very low value of $R_{\mathrm{t}}$ is one of the unique properties of this segment, as previously noticed (Hoshi et al., 1981b). The value of $31.0 \Omega \cdot \mathrm{cm}^{2}$ is about one fifth that of the proximal tubule of the Triturus kidney, which has a value of 150 $160 \Omega \cdot \mathrm{cm}^{2}$ (Hoshi et al., 1981a). $R_{\mathrm{t}}$ is the sum in parallel of the transcellular resistance (the apical and basolateral membrane resistances in series) and the paracellular shunt resistance. Quantitative determination of these resistances has not been made for this segment because of technical difficulties caused by the small sizes of cells. In this study, input resistances measured in the cells of this segment were compared with those of the proximal tubule. The resistance of this segment was 5.8 times higher than that of the proximal tubule. This ratio was about 2 times higher than the reciprocal of the ratio of cell surface area of the segment to that of the proximal tubule. Although fine structures such as microvilli and membrane infoldings were neglected in surface area measurements, the higher ratio of the input resistances rules out the possibility that the low value of $R_{\mathrm{t}}$ is due to the leakiness of the cell membranes. It seems more reasonable to conclude that the membrane resistances of this segment are of the same order of magnitude as those of the proximal tubule $\left(2,000 \Omega \cdot \mathrm{cm}^{2}\right.$ for the apical membrane and $3,000 \Omega \cdot \mathrm{cm}^{2}$ for the basolateral membrane, HosHI et al., 1981a) and that low $R_{\mathrm{t}}$ is due to leakiness of the paracellular pathway. Very large amplitudes of $\mathrm{K}^{+}$ diffusion potential near the maximum value expected from the concentration gradient is easily explained if we assume that it is generated across the paracellular pathways or intercellular junctional complexes.

Transepithelial $\mathrm{K}^{+}$and $\mathrm{Na}^{+}$diffusion potentials recorded in the present study revealed that the permeation pathway was permeable to $\mathrm{K}^{+}, \mathrm{Na}^{+}$, and $\mathrm{Cl}^{-}$, the relative permeability to these ions being $P_{\mathrm{K}}>P_{\mathrm{Na}}>P_{\mathrm{C} 1}$. Using the measured values of the peak amplitude of $\mathrm{K}^{+}$and $\mathrm{Na}^{+}$diffusion potentials and Henderson's equation, $\left(U_{\mathrm{K}}-U_{\mathrm{C} 1}\right) /\left(U_{\mathrm{Na}}-U_{\mathrm{C} 1}\right)$ ratio $(U$ : mobility of ions) may be determined as $2.8(=32.0 / 11.5)$. When $\mathrm{NaCl}$ in the perfusion solution was totally replaced by Tris-Cl, $R_{\mathrm{t}}$ increased from 31 to $160 \Omega \cdot \mathrm{cm}^{2}$. Although Tris conductance of the putative site is unknown, an almost 5-fold increase of $R_{\mathrm{t}}$ observed after total replacement of $\mathrm{Na}^{+}$by Tris indicates that $U_{\mathrm{Na}} / U_{\mathrm{Cl}}$ is not less than 5 . From these values, $P_{\mathrm{K}}$ is considered to be about 3 times higher than $P_{\mathrm{Na}}$ and at least 12 times higher than $P_{\mathrm{C} 1}$. On the other hand, other leaky epithelia, such as the renal proximal tubule (Frömter, 1977) and the small intestine (Frizzell and Schultz, 
1972) have been shown to have a higher conductance for monovalent cations than for anions but no selectivity between $\mathrm{K}^{+}$and $\mathrm{Na}^{+}$, the ratio of $P_{\mathrm{K}}: \mathrm{P}_{\mathrm{Na}}: P_{\mathrm{C} 1}$ being approximately $1: 1: 0.5$. Thus, the low resistance pathway of the present preparation reveals different permeability characteristics when compared with other leaky epithelia. At present, we have no explanation for such differences based on morphological and/or molecular properties, but it is attractive to speculate that such special permeability characteristics have a close relation to physiological necessities of $\mathrm{K}^{+}$movements into the lumen to maintain intraluminal $\mathrm{K}^{+}$concentrations in this particular nephron segment.

In the present study, $\mathrm{K}^{+}$movement was created under special experimental conditions, i.e. in the presence of an artificially imposed secretory gradient of $\mathrm{K}^{+}$ across the tubular wall. Under physiological conditions, intraluminal $\mathrm{K}^{+}$concentrations may be maintained at a high level by $\mathrm{K}^{+}$supply in the presence of a small secretory driving force for $\mathrm{K}^{+}$. However, the real situation does not seem to be so simple. Teulon et al. (1985) recently demonstrated that, in in situ experiments in Triturus, $\mathrm{K}^{+}$activity in the luminal fluid was $4 \mathrm{~mm}$ at the initial third, $3.8 \mathrm{~mm}$ at the middle and $3.0 \mathrm{~mm}$ at the late third. In their observations, $\mathrm{K}^{+}$ activity of the peritubular fluid was $2.5 \mathrm{~mm}$ and the lumen was electrically positive by about $16-20 \mathrm{mV}$ along the entire length of the tubule. Accordingly, a reabsorptive driving force for $\mathrm{K}^{+}$was present along the entire segment. Furthermore, their data suggest that, even across the luminal membrane, a reabsorptive driving force is acting on $\mathrm{K}^{+}$. Assuming an intracellular $\mathrm{K}^{+}$activity of at most $75 \mathrm{~mm}$, their data on intraluminal $\mathrm{K}^{+}$activity allows an estimate of the $\mathrm{K}^{+}$equilibrium potential of 71-78 mM. The value of $V_{\mathrm{a}}$ is usually greater than $80 \mathrm{mV}$ in the Triturus kidney ( $83.4 \mathrm{mV}$ in the present estimation). Therefore, intraluminal $\mathrm{K}^{+}$activity higher than $3.0 \mathrm{~mm}$ can not be simply explained by passive electrodiffusion of $\mathrm{K}^{+}$into the lumen.

On the basis of the present findings and the data of TEulon et al. (1985), we propose the following mechanism of $\mathrm{K}^{+}$entry to the lumen. In the presence of the cotransport activity, there is a local pool of $\mathrm{K}^{+}$in the paracellular pathway in the vicinity of the junctional region, where $\mathrm{K}^{+}$concentrations are higher than in luminal and peritubular fluids. Even in the presence of a lumen-positive $V_{\mathrm{t}}, \mathrm{K}^{+}$ concentrations in the pool of about $7-8 \mathrm{~mm}$ will cause $\mathrm{K}^{+}$movement into the lumen, if the junctional region is permeable to $\mathrm{K}^{+}$. Part of the $\mathrm{K}^{+}$of the local pool diffusing toward the peritubular fluid is recaptured by the basolateral $\mathrm{Na}^{+}$, $\mathrm{K}^{+}$pump and thus recycled.

$\mathrm{Ba}^{2+}$ had no effect on $V_{\mathrm{t}}$ when the $2 \mathrm{Cl}^{-} / \mathrm{Na}^{+} / \mathrm{K}^{+}$cotransport was absent. If the luminal membrane has $\mathrm{Ba}^{2+}$-sensitive $\mathrm{K}^{+}$conductance and some permeability to $\mathrm{Na}^{+}$and $\mathrm{Cl}^{-}$, addition of $\mathrm{Ba}^{2+}$ to the luminal side should cause some change in $V_{t}$, depending on the ratio of the resistances of the basolateral membrane and the paracellular shunt. The presence of $\mathrm{Ba}^{2+}$-sensitive $\mathrm{K}^{+}$conductance at the luminal membrane has been suggested by GrEGER and SCHLATTER (1983) and 
GugGino et al. (1982). Accordingly, the failure of $\mathrm{Ba}^{2+}$ to affect $V_{\mathrm{t}}$ may be ascribed either to the absence of luminal membrane permeability to other ion species or to a large resistance ratio between the basolateral membrane and the paracellular shunt.

In the presence of coupled ion transport $(\mathrm{Na} / \mathrm{K} / 2 \mathrm{Cl})$ and resultant $I_{\mathrm{sc}}, \mathrm{Ba}^{2+}$ inhibited both $I_{\mathrm{sc}}$ and $V_{\mathrm{t}}$. The concentration-dependent inhibition of $I_{\mathrm{sc}}$ was the mirror-image of the increase of $R_{\mathrm{t}}$, when plotted against $\mathrm{Ba}^{2+}$ concentrations. The inhibition of $I_{\mathrm{sc}}$ and $V_{\mathrm{t}}$ by $\mathrm{Ba}^{2+}$ in the presence of the cotransport can be regarded as the result of inhibition of $\mathrm{K}^{+}$current flowing across the junctional region, probably by the mechanism suggested above. The magnitude of $I_{\mathrm{se}}$ is dependent on the coupled influxes of $\mathrm{Cl}^{-}, \mathrm{Na}^{+}$, and $\mathrm{K}^{+}$and the relationship of both can be clearly defined kinetically (Hoshi et al., 1984). The coupled entry process is known to be electroneutral because of the neutralization of net charges. Therefore, the $I_{\mathrm{sc}}$ has been thought to be mainly determined by $\mathrm{Cl}^{-}$exit through a conductive pathway for $\mathrm{Cl}^{-}$present in the basolateral membrane. The presence of such an $\mathrm{Cl}^{-}$pathway in the basolateral membrane has been demonstrated by inhibition experiments with antracene-9-carboxylic acid (OBERLEITHNER et al., 1983b). However, our findings on the inhibitory action of intraluminally applied $\mathrm{Ba}^{2+}$ on both $I_{\mathrm{sc}}$ and transtubular electrical conductance suggest that at least a part of $I_{\mathrm{sc}}$ is carried by $\mathrm{K}^{+}$flowing across the paracellular path in the opposite direction to that of overall $\mathrm{Cl}^{-}$movement.

We thank Dr. T. Anagnostopoulos for his kind reviewing of the manuscript and corrections. This work was supported by the Grants-in-Aid (57480101, 58370004) from the Ministry of Education, Science and Culture of Japan.

\section{REFERENCES}

Bentzel, C. J., Hainau, B., Edelman, A., Anagnostopoulos, T., and Benedetti, E. L. (1976) Effect of plant cytokinins on microfilaments and tight jucntion permeability. Nature, 264: 666-668.

Biagi, B., Sohtell, M., and Giebisch, G. (1981) Intracellular potassium activity in the rabbit straight tubule. Am. J. Physiol., 241: F677-F686.

FrizZell, R. A. and Schultz, S. G. (1972) Ionic conductances of extracellular shunt pathway in rabbit ileum. J. Gen. Physiol., 59: 318-346.

FröMTER, E. (1977) Magnitude and significance of the paracellular shunt path in rat kidney proximal tuble. In: Intestinal Permeation, ed. by Kramer, M. and LAUterbach, F., Excerpta Medica, Amsterdam/Oxford, pp. 393-405.

Greger, R. and Shlatter, E. (1983) Properties of the luminal membrane of the thick ascending limb of Henle's loop of rabbit kidney. Pflügers Arch., 396: 315-324.

Greger, R. and ShlatTER, E. (1984) Mechanisms of chloride transport in vertebrate renal tublue. In: Chloride Transport Coupling in Biological Membranes and Epithelia, ed. by Gerencser, C. A. G., Elsevier, Amsterdam/New York/Oxford, pp. 271-346.

Greger, R., Shlatter, E., and LANG, F. (1983) Evidence for electroneutral sodium chloride cotransport in the cortical thick ascending limb of Henle's loop of rabbit kindey. Pflügers Arch., 396: 308-314. 
Guggino, W. B., Stanton, B. A., and Giebisch, G. (1982) Regulation of apical potassium conductance in isolated early distal tubule of Amphiuma kidnely. Biophys. J., 37: 338 (abstract).

Hoshi, T., Kawahara, K., Yokoyama, R., and Suenaga, K. (1981a) Changes in membrane resistances of renal proximal tubule induced by cotransport of sodium and organic solute. In: Advances in Physiological Sciences, Vol. 11, Kidney and Body Fluid, ed. by TAKAcs, L., Pergamon Press, Budapest, pp. 403-407.

Hoshi, T., Kuramochi, G., and SaKamoto, H. (1984) Kinetic properties of active $\mathrm{Cl}^{-}$transport across amphibian early distal tubule. In: Coupled Transport in Nephron-Mechanisms and Pathophysiology, ed. by HoshI, T., Miura Med. Foundation, Tokyo, pp. 131-142.

Hoshi, T., Kuramochi, G., and Yoshitomi, K. (1983) Lumen-positive chloride transport potential in the early distal tubule of Triturus kidney: Its absolute dependence on the presence of $\mathrm{Na}^{+}$and $\mathrm{K}^{+}$in the luminal fluid. Jpn. J. Physiol., 33: 855-861.

Hoshi, T., Suzuki, Y., and IToI, K. (1981b) Differences in functional properties between the early and the late segments of the distal tubule of amphibian (Triturus) kidney. Jpn. J. Nephrol., 23: 889-896.

KönING, B., RicAPITo, S., and KINNE, R. (183) Chloride transport in the thick ascending limb of Henle's loop: Potassium dependence and stoichiometry of the $\mathrm{NaCl}$ cotransport system in plasma membrane vesicles. Pflügers Arch., 399: 173-179.

Macknight, A. D. C., Dibona, D. R., and Leaf, A. (1980) Sodium transport across toad urinary bladder: A model "tight" epithelium. Physiol. Rev., 60: 615-715.

Moreno, N. H. (1975) Blockage of gallbladder tight junction cation-selective channels by 2,4,6triaminopyrimidium (TAP). J. Gen. Physiol., 66: 97-115.

Oberleithner, H., Guggino, W., and Giebisch, G. (1982) Mechanism of distal tubular chloride transport in amphibian kidney. Am. J. Physiol., 242: F331-F339.

Oberleithner, H., Guggino, W., and Giebisch, G. (1983a) The effect of furosemide on luminal sodium, chloride and potassium transport in the early distal tubule of an amphibian kidney. Pflügers Arch., 396: 27-33.

Oberleithner, H., Ritter, M., LANG, F., and Guggino, W. (1983b) Antracence-9-carboxylic acid inhibits renal chloride reabsorption. Pflügers Arch., 398: 172-174.

O'NeIL, R. G. (1983) Voltage-dependent interaction of barium and cesium with the potassium conductance of the cortical collecting duct apical cell membrane. J. Membr. Biol., 74: 165173.

Stoner, L. C. (1977) Isolated, perfused amphibian renal tubules: The diluting segment. Am. J. Physiol., 233: F438-F444.

Teulon, J. and Anagnostopoulos, T. (1982) The electrical profile of the distal tubule of Triturus kidney. Pflügers Arch., 395: 138-144.

Teulon, J., Froissart, P., and Anagnostopoulos, T. (1985) Electrochemical profile of $\mathrm{K}^{+}$and $\mathrm{Na}^{+}$in the amphibian early distal tubule. Am. J. Physiol., 248: F266-F271.

Wright, E. M. and Diamond, J. M. (1968) Effects of $\mathrm{pH}$ and polyvalent cations on the selective permeability of gallbladder epithelium to monovalent ions. Biochim. Biophys. Acta, 163: 57-74.

Vol. 35, No. 6, 1985 